\title{
Clinical Outcomes and Prognostic Factors of Salvage Treatment for Local Lymph Node Recurrence After Radical Resection of Oesophageal Carcinoma
}

\author{
Liang Gu id ${ }^{1,2}$ \\ Yangchen Liu ${ }^{2}$ \\ Hongxue $\mathrm{Ye}^{2}$ \\ Fei $\mathrm{Gao}^{2}$ \\ Xiaoxiang Yin ${ }^{2}$ \\ Ying Zhao ${ }^{2}$ \\ Ye Tian' \\ 'Department of Radiation Oncology, The \\ Second Affiliated Hospital of Soochow \\ University, Su Zhou, 215004, Jiang Su \\ Province, People's Republic of China; \\ ${ }^{2}$ Department of Radiation Oncology, \\ Taixing People's Hospital, Tai Xing, \\ 225400, Jiang Su Province, People's \\ Republic of China
}

\begin{abstract}
Background: There are no standard therapeutic strategies for local lymph node (LN) recurrence after radical resection of oesophageal squamous cell carcinoma (ESCC), and prognostic risk factors remain controversial. We assessed clinical outcomes and prognostic factors of chemoradiotherapy (CRT) or radiotherapy (RT) for LN recurrence of ESCC after curative resection.

Methods: A total of 117 ESCC patients with LN recurrence after radical resection receiving salvage treatment at our hospital were retrospectively reviewed from 2014 to 2017 . Overall survival (OS) was estimated using the Kaplan-Meier method; clinical characteristics were assessed using the Log rank test in the univariate analysis. Multivariate prognostic analysis was performed using the Cox proportional hazard model.

Results: With a median follow-up of 19 months, the 1-, 2- and 3-year OS rates were 75.2\%, $40.2 \%$ and $27.4 \%$, respectively. The median survival time (MST) was 19.0 months. On univariate analysis for OS, pathological TNM stage, number of LN metastasis, LN maximum (Max) diameter, salvage treatment mode and tumor response were significantly associated with $\mathrm{OS}(\mathrm{P}=0.0074, \mathrm{P}=0.015, \mathrm{P}=0.0011, \mathrm{P}=0.028, \mathrm{P}<0.000$, respectively). On multivariate analysis, tumor response [Response vs No-response hazard ratio (HR), 2.43; 95\% confidence interval $(\mathrm{CI}), 1.53-3.90, \mathrm{P}<0.000]$ and $\mathrm{LN}$ Max diameter $(\leq 28 \mathrm{~mm}$ vs $>28 \mathrm{~mm}$ HR, 2.07; 95\% CI, 1.33-3.32, $\mathrm{P}=0.012$ ) were independent prognostic factors.

Conclusion: Salvage CRT or RT was safe and effective for treating LN recurrence after radical resection in ESCC. Patients with the small LN Max diameter $(\leq 28 \mathrm{~mm})$ and obtained response after salvage therapy appeared to achieve long-term OS.
\end{abstract}

Keywords: oesophageal cancer, lymph node recurrence, chemoradiotherapy

\section{Introduction}

Oesophageal cancer (EC) is the seventh most common cancer and the sixth most common cause of cancer-related deaths worldwide. ${ }^{1}$ Oesophagectomy remains a standard treatment for resectable oesophageal cancer. However, lymph node (LN) recurrence is one of the main types of treatment failure and is noted in up to $23.8-58.0 \%$ of cases. The most common LN recurrence sites are supraclavicular lymph nodes and mediastinal lymph nodes; the median time to recurrence ranges from 10 to 12 months. $^{2-7}$ Although chemotherapy alone or best supportive care can prolong survival, the outcomes in patients treated with chemotherapy alone were
Correspondence: Ye Tian

Department of Radiation Oncology, The Second Affiliated Hospital of Soochow University, 1005 Sanxiang Road, Su Zhou, 215004, Jiang Su Province, People's

Republic of China

Email dryetian@126.com 
significantly worse than in patients treated with other therapies. ${ }^{8,9}$ Therefore, chemotherapy alone or best supportive care is usually not first reserved for patients with LN recurrence. For cervical lymph node recurrence or solitary lymph node recurrence, lymphadenectomy is considered a good salvage option and may offer a survival benefit for appropriately selected patients. ${ }^{9-12}$ When surgery is not an option or contraindicated, radiotherapy (RT) or radiochemotherapy (CRT) show promising results in controlling lymph node recurrence after curative resection. RT is effective for the relief of symptoms, ${ }^{13}$ and several studies have verified the effectiveness of CRT to achieve long-term survival. ${ }^{14-17}$ However, the most effective therapeutic strategies are inconclusive, and the most accurate prognostic risk factors are controversial for $\mathrm{LN}$ recurrence of EC.

We mainly perform CRT or RT for LN recurrence of oesophageal squamous cell carcinoma (ESCC) after curative oesophagectomy at our hospital. This retrospective study aimed to evaluate clinical outcomes and prognostic factors related to the use of CRT or RT for LN recurrence after curative resection of ESCC.

\section{Materials and Methods Study Population}

We retrospectively reviewed the medical records, RT treatment plans and diagnostic images of patients who underwent CRT or RT for postoperative regional lymph node recurrence after curative oesophagectomy in Taixing People's Hospital, Jiangsu, China, from October 2014 to October 2017. The inclusion criteria were as follows: (a) curative oesophagectomy with 2- or 3-field LN dissection and pathologically confirmed SCC; (b) initial treatment received without prior or postoperative radiotherapy; (c) diagnosis of recurrence within the bilateral supraclavicular region and mediastinum using ultrasonography, computed tomography (CT), positron emission tomography (PET) or histological confirmation by biopsy; (d) Eastern Cooperative Oncology Group (ECOG) performance status of $0-2$ and no clear contraindications to radiotherapy and chemotherapy. Exclusion criteria were anastomotic recurrence, $L N$ recurrence at the abdominal level and distant metastasis. Finally, 117 patients were enrolled in the study. The study was approved by the ethics committee of Taixing people's Hospital and all patients provided informed consent.

\section{Treatment}

All patients received three-dimensional conformal RT (3DCRT). With the patient in the supine position, a cradle for immobilisation was made with vacuum. Each patient was scanned from the Atlas (C1) to the second lumbar vertebra (L2) level to cover the entire neck, lung and oesophagus. CT enhancement scans were performed with $5 \mathrm{~mm}$ thickness slices, and the images were transferred to the Treatment Planning System (TPS) to determine the target area and the radiation therapy plan. The gross tumour volume (GTV) was defined as recurrent lymph nodes identified by CT scans or PET/CT. Two clinical target volumes (CTV) were defined. The extended-field (T-shaped field) CTV (CTV1) included the bilateral supraclavicular and mediastinal regions (station 1-5 and 7 lymph nodes $)^{6}$ and GTV plus a margin of $10 \mathrm{~mm}$ around GTV. The involved-field CTV (CTV2) only included GTV plus a margin of $10 \mathrm{~mm}$ around GTV. The planning tumour volume (PTV) was defined as the CTV plus the placement of $5 \mathrm{~mm}$ around the CTV. PTV1 and PTV2 were defined by CTV1 and CTV2. The extended-field prescription dose was 50 Gy to PTV1 and then adding 8-14 Gy dose to PTV2. The median dose was 60 Gy to PTV2 (range from 50 to $64 \mathrm{~Gy}$ ) in the involved-field. All patients were treated with a 6-MV linear accelerator. The daily fractional dose of RT was 1.8-2.0 Gy, 5 days per week. Dose constraint for critical organs was administered as follows: maximum dose of spinal cord $<46$ Gy, mean lung dose $<17$ Gy and V20 $<30 \%$, mean heart dose $<35$ Gy. The extendedfield RT was used for 28 patients and the involved-field RT for 89 patients.

Thirty-one patients received RT alone, and the remaining 86 patients received combination of RT with chemotherapy. Among them, 22 patients received chemotherapy sequentially following RT, 16 patients received CRT without sequential chemotherapy, and 48 patients received consolidation chemotherapy after CRT. The concurrent chemotherapy regimen included paclitaxel (T; $135-175 \mathrm{mg} / \mathrm{m}^{2}$ on Day 1 for 4 weeks) plus cisplatin (CDDP; $25 \mathrm{mg} / \mathrm{m}^{2}$ on Day $1-3$ for 4 weeks) in 41 patients, $\mathrm{T}(45-50 \mathrm{mg} / \mathrm{m} 2$ on Day 1 for 1 week) alone in 21 patients and Tegafur Gimeracil Oteracil Potassium Capsule (S1) alone in 2 patients. The sequential chemotherapy regimen consisted of TP (T plus CDDP) in 67 patients and 5-fluorouracil + CDDP in 3 patients, administered in 2-4 cycles. 


\section{Follow-Up and Response Assessment}

The beginning of the follow-up period was defined as the last date of RT. All the patients were followed-up at 1- or 3-month intervals. Follow-up evaluations included contrasted CT of the neck, thorax and upper abdomen, ultrasonography of the neck and upper abdomen and nuclear bone scanning. Additionally, endoscopy, magnetic resonance, PET or cytologic puncture was needed. The Response Evaluation Criteria in Solid Tumours (version $1.1)^{18}$ were used to determine tumour response. Toxicity was assessed using the National Cancer Institute Common Terminology Criteria for Adverse Events (CTCAE 4.0).

\section{Statistical Analysis}

The study endpoint was overall survival (OS), defined as the interval between LN recurrence and death from any cause, loss to follow-up or last follow-up. OS was estimated using the Kaplan-Meier method, and the differences in survival in the univariate analysis were assessed with the $\log$ rank test. P-values of $<0.05$ in the univariate analysis were included in the multivariable models. Multivariate analysis for OS was performed with a Cox proportional hazards model, and the variables were selected by the stepwise method. P-values $<0.05$ were considered indicative of statistical significance. All the statistical analyses were performed using $\mathrm{R}$ software (version 3.5.3, http://www.r-project.org/).

\section{Results}

\section{Patients and Tumour Characteristics}

A summary of patient and tumour characteristics is detailed in Table 1. Primary histopathological diagnosis of squamous cell carcinoma was established for all patients. The median age was 64 years (range, 46-80 years). The male-to-female ratio was 97:20. The primary tumour location was the upper thoracic region in 6 patients, middle thoracic in 80 patients and lower thoracic in 31 patients. The post-resection pathological stage I was present in 23 patients, stage II in 39 patients and stage III in 55 patients. The median interval time between surgery for the primary lesion to identifying $\mathrm{LN}$ recurrence was 11 months (range, 1-120 months). The median LN maximum (Max) diameter, defined as the longest diameter of the recurrence $\mathrm{LN}$ in the axial plane in $\mathrm{CT}$, was $28 \mathrm{~mm}$ (range, 6-67 mm). Ten patients developed supraclavicular LN recurrence, and 98 patients showed mediastinal LN recurrence; 9 patients had both regions involved. Eighty patients had single LN metastasis, and 37 had multiple LN metastases. Only 48 patients received postoperative prophylactic chemotherapy.

\section{Treatment Outcome}

With a median follow-up of 19 months (range, 4-70 months), the 1-, 2- and 3-year OS rates were $75.2 \%$ [95\% confidence interval (CI), 67.8-83.5], 40.2\% (95\% CI, 32.2-50.1) and $27.4 \%$ (95\% CI, 20.3-30.6), respectively. The median survival time (MST) was 19.0 months. The overall response rate (including complete responses and partial responses) was $70.0 \%(82 / 117)$ in all patients, $62.2 \%(33 / 53)$ in $\mathrm{RT} \pm \mathrm{C}$ patients and $76.5 \%(49 / 64)$ in $\mathrm{CRT} \pm \mathrm{C}$ patients. The response group had a better OS than the non-response group $(\mathrm{p}=0.00024$, Figure 1$)$.

\section{Toxicity}

G3 neutropenia was observed in 22 patients (34.3\%) in the $\mathrm{CRT} \pm \mathrm{C}$ group and 11 patients $(20.7 \%)$ in the RT \pm $\mathrm{C}$ group. Grade 3 oesophagitis or gastritis was noted in 6 patients (9.3\%) in the CRT $\pm \mathrm{C}$ group; $\mathrm{G} 3$ vomiting was observed in 9 out of 64 patients (14.1\%) in the CRT \pm C group. No Grade 4 or 5 toxicities were present in any patient, and there were no treatment-related deaths.

\section{Analysis of Survival}

On univariate analysis for OS, pathological TNM stage, number of LN metastasis, LN Max diameter, salvage treatment mode and tumor response were significantly associated with $\mathrm{OS}(\mathrm{P}=0.0074, \mathrm{P}=0.015, \mathrm{P}=0.0011$, $\mathrm{P}=0.028, \mathrm{P}<0.000$, respectively) (Table 1 ). The 3 -year OS was $52.2 \%$ (95\% CI: 35.3-77.2\%), $23.1 \%$ (95\% CI: $13.0-40.9 \%)$ and $18.2 \%$ (95\% CI: $10.4-31.9 \%)$ in pathological Ia + Ib, IIa + IIb and IIIa + IIIb groups, respectively. The patients in the Ia $+\mathrm{Ib}$ group had a better prognosis than those in the IIa + IIb and IIIa + IIIb groups ( $\mathrm{P}=0.0074,0.049$, respectively), but there was no difference in survival time between IIa + IIb and IIIa + IIIb groups ( $\mathrm{P}=0.12$, Figure 2$)$. The $\mathrm{CRT} \pm \mathrm{C}$ group achieved a 3-year OS of $29.7 \%$ (95\% CI: $20.0-43.3 \%$ ) compared to $22.6 \%$ (95\% CI: $13.8-37.2 \%)$ for $\mathrm{RT} \pm \mathrm{C}(\mathrm{P}=0.028)$. In the subgroup analysis, the 3-year OS and MST were $22.6 \%$ and 13.0 months, $22.7 \%$ and 17.5 months, $25.0 \%$ and 24.0 months and $31.2 \%$ and 22.5 months in RT, RT + $\mathrm{C}$, CRT and CRT $+\mathrm{C}$ groups, respectively. The survival of the CRT $+\mathrm{C}$ group was longer than that of the RT group $(\mathrm{P}=0.031)$. There was no statistical difference in the other groups (Figure 3). There was no statistical difference in 
Table I Patient Clinical Characteristics and Univariate Analysis

\begin{tabular}{|c|c|c|c|}
\hline Factor & $\begin{array}{l}\text { No. I I } 7 \\
\text { (\%) }\end{array}$ & $\begin{array}{l}\text { MST } \\
\text { (Month) }\end{array}$ & P-value \\
\hline \multicolumn{4}{|l|}{ Sex } \\
\hline Male & $97(82.9)$ & 18 & 0.32 \\
\hline Female & $20(17.1)$ & 19.5 & \\
\hline \multicolumn{4}{|l|}{ Age, years } \\
\hline$\leq 64$ & $65(55.5)$ & 24 & 0.098 \\
\hline$>64$ & $52(44.5)$ & 16 & \\
\hline \multirow{2}{*}{\multicolumn{4}{|c|}{$\begin{array}{l}\text { Performance status } \\
\text { (ECOG) }\end{array}$}} \\
\hline & & & \\
\hline 0 & $21(17.9)$ & 20 & 0.16 \\
\hline 1 & $73(62.4)$ & 20 & \\
\hline 2 & $23(19.7)$ & 15 & \\
\hline \multicolumn{4}{|l|}{ Primary tumour location } \\
\hline Upper & $6(5.1)$ & 28 & 0.62 \\
\hline Middle & $80(68.4)$ & 17.5 & \\
\hline Lower & $31(26.5)$ & 20 & \\
\hline \multicolumn{4}{|l|}{ Radical surgery } \\
\hline Two-fields resection & $102(87.2)$ & 18.5 & 0.82 \\
\hline There-fields resection & $15(12.8)$ & 19 & \\
\hline \multicolumn{4}{|l|}{ Differentiation degree } \\
\hline Well & II (9.4) & 26 & 0.23 \\
\hline Median & $87(74.4)$ & 19 & \\
\hline Poor & $19(16.2)$ & 14 & \\
\hline \multicolumn{4}{|l|}{ Pathological TNM stage* } \\
\hline $\mathrm{la}+\mathrm{lb}$ & $23(19.7)$ & NA & 0.0074 \\
\hline $\mathrm{Ila}+\mathrm{Ilb}$ & $39(33.3)$ & 22 & \\
\hline $\mathrm{IIla}+\mathrm{IIlb}$ & $55(47.0)$ & 16 & \\
\hline \multicolumn{4}{|l|}{$\mathrm{LN}$ recurrence site } \\
\hline Supraclavicular & 10 & 21 & 0.74 \\
\hline Mediastinal & 98 & 18 & \\
\hline Both & 9 & 17 & \\
\hline \multicolumn{4}{|l|}{ Interval to recurrence } \\
\hline SII months & $55(47.0)$ & 18 & 0.78 \\
\hline$>1$ I months & $62(53.0)$ & 19.5 & \\
\hline \multicolumn{4}{|l|}{ No. of $L N$ metastasis } \\
\hline Mono & $80(68.4)$ & 22 & 0.015 \\
\hline Multiple & $37(31.6)$ & 16 & \\
\hline \multicolumn{4}{|l|}{ LN Max diameter } \\
\hline$\leq 28 \mathrm{~mm}$ & $62(53.0)$ & 25.5 & 0.0011 \\
\hline$>28 \mathrm{~mm}$ & $55(47.0)$ & 16 & \\
\hline \multicolumn{4}{|l|}{ POST-C } \\
\hline Yes & $48(41.0)$ & 19.5 & 0.97 \\
\hline No & $69(59.0)$ & 17 & \\
\hline \multicolumn{4}{|l|}{ Salvage Treatments } \\
\hline $\mathrm{RT} \pm \mathrm{C}$ & $53(45.3)$ & 16 & 0.028 \\
\hline
\end{tabular}

(Continued)
Table I (Continued).

\begin{tabular}{|c|l|l|l|}
\hline Factor & $\begin{array}{l}\text { No. II7 } \\
\text { (\%) }\end{array}$ & $\begin{array}{l}\text { MST } \\
\text { (Month) }\end{array}$ & P-value \\
\hline CRT \pm C & $64(54.7)$ & 22.5 & \\
\hline $\begin{array}{c}\text { Irradiation field } \\
\text { Involved-field } \\
\text { Extended-field }\end{array}$ & $89(76.1)$ & 20 & 0.22 \\
\hline $\begin{array}{c}\text { Radiation dose } \\
\geq 60 \text { Gy } \\
<60 \text { Gy }\end{array}$ & $92(78.6)$ & 20 & 0.095 \\
\hline $\begin{array}{c}\text { Tumor response } \\
\text { Response (CR+PR) } \\
\text { No-response (SD+PD) }\end{array}$ & $82(70.0)$ & 24.5 & 0.000 \\
\hline
\end{tabular}

Note: *AJCC 8th edition.

Abbreviations: No., number; MST, median survival time; $\mathrm{Cl}$, confidence interval; LN, lymph node; POST-C, postoperative adjuvant chemotherapy; C, chemotherapy; RT, radiotherapy; CRT, chemoradiation; $C R$, complete response; PR, partial response; $\mathrm{SD}$, stable disease; $\mathrm{PD}$, progressive disease.

OS between the concurrent chemotherapy regimens $\mathrm{T}$ and TP in 48 patients who received CRT and consolidation chemotherapy ( $\mathrm{P}=0.25$, see Supplementary Materials Fig.s1). The 3-year OS and MST were 39.7\% and 25.5 months for LN Max diameter $\leq 28 \mathrm{~mm}$, compared to $14.5 \%$ and 16 months for $\mathrm{LN}$ Max diameter $>28 \mathrm{~mm}(\mathrm{p}$ $=0.0011$, Figure 4).

On multivariate analysis, tumor response [Response vs No-response hazard ratio (HR), 2.43; 95\% confidence interval (CI), 1.53-3.90, $\mathrm{P}<0.000]$ and LN Max diameter ( $\leq 28 \mathrm{~mm}$ vs $>28 \mathrm{~mm}$ HR, $2.07 ; 95 \% \mathrm{CI}, 1.33-3.32, \mathrm{P}=$ 0.012 ) were independent prognostic factors (Table 2).

\section{Discussion}

Previous studies suggested that successful management of initial LN recurrence provided survival benefits for postoperative LN recurrence of oesophageal cancer., ${ }^{9,19} \mathrm{Ni}$ et $\mathrm{al}^{7}$ evaluated the therapeutic efficacy of salvage therapy along with the prognostic factors in LN recurrent after radical esophagectomy. The 3-year OS rates was only $2.9 \%$ with chemotherapy alone or best supportive care, significantly worse than those treated with salvage RT or CRT. The patients after curative resection of ESCC treated with the salvage lymphadenectomy for supraclavicular recurrence LN had better OS than those treated with the salvage RT or CRT in $\mathrm{Ni}^{7}$ and Nakamura ${ }^{8}$ studies. But the report of the salvage lymphadenectomy for mediastinal LN was seldom. Although optimal salvage strategies in 

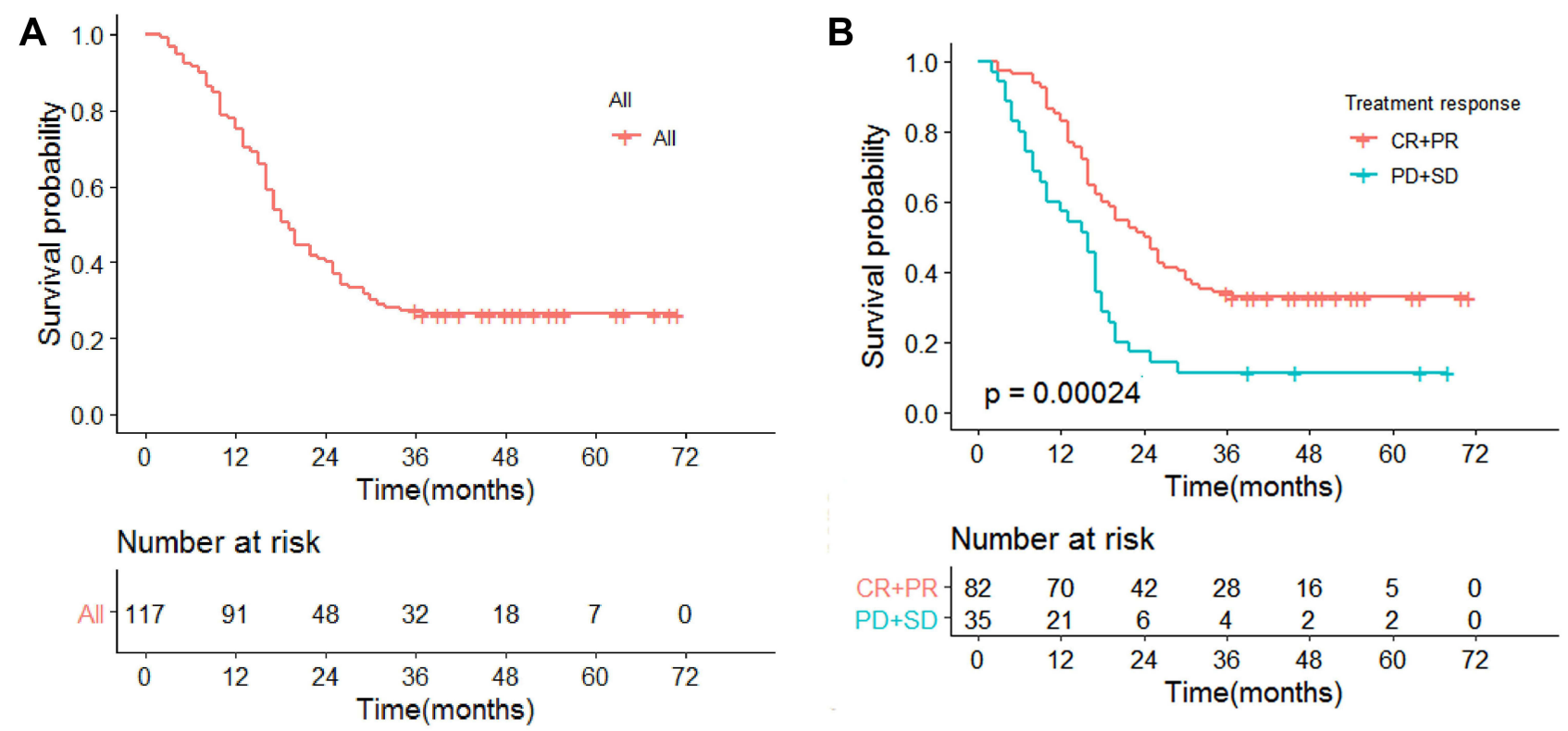

Figure I (A) Overall survival curves for all patients; (B) Overall survival of patients with different treatment responses.

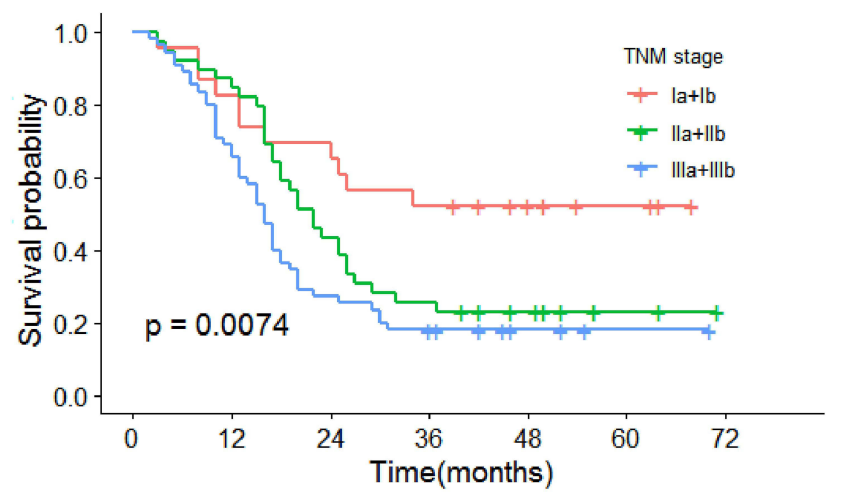

Number at risk

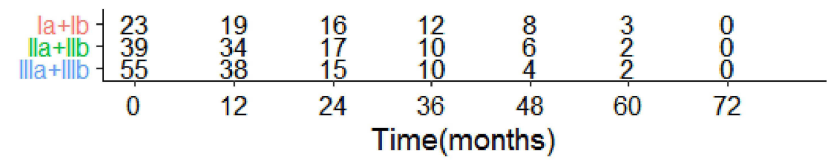

Figure 2 Kaplan-Meier estimates of overall survival for pathological TNM stage.

patients with LN recurrence remain controversial, many retrospective studies suggest that RT or CRT is an effective and feasible salvage treatment for LN recurrence after radical resection of ESCC, particularly CRT. ${ }^{7,14-17,20-23}$

CRT appears to be superior to RT in OS for treating the locoregional recurrence of esophageal cancer after curative resection in most studies, but some studies found that CRT may not improve treatment outcomes compared to RT alone. A multi-institutional study of 237 patients for lymph node oligo-recurrence of oesophageal cancer by
Yamashita et $\mathrm{al}^{14}$ found that the 3-year OS was 39.7\% with an MST of 26 months in patients receiving CRT; the 3 -year OS was $20.8 \%$ with an MST of 10.8 months with RT alone $(p=0.000055)$. However, Chen et $\mathrm{a}^{17}$ retrospectively analysed 83 patients with LN recurrence after radical resection of ECSS and observed that the 3-year OS was $47.5 \%$ in patients treated with RT alone and $41.9 \%$ in patients receiving CRT $(\mathrm{p}=0.570)$. In this study, the MST was 19.0 months, and the 3-year OS was 27.4\% (95\% CI, 20.3-30.6). The CRT $\pm \mathrm{C}$ group achieved a 3-year OS of $29.7 \%$ (95\% CI: $20.0-43.3 \%$ ) compared to $22.6 \%(95 \% \mathrm{CI}: 13.8-37.2 \%)$ for $\mathrm{RT} \pm \mathrm{C}(\mathrm{P}=0.028)$, consistent with the reports of $\mathrm{Ni}^{7}$ and Zhou. ${ }^{16}$

Several prognostic factors, such as age, postoperative TNM stage, LN Max diameter, GTV volume of radiation, number of LN recurrence, irradiation dose and combined chemotherapy regimen, have been reported (Supplementary Materials Table.s1)..$^{714-17,20,22-24}$ In the Yamashita et $\mathrm{al}^{14}$ study, a total of 237 patients with LN oligo-recurrence (from 1 to $5 \mathrm{LN}$ recurrences) of ESCC were treated with RT or CRT. They found that the 3-year OS was $42.1 \%$ for LN Max diameter $\leq 22 \mathrm{~mm}$ and $30.2 \%$ for $\mathrm{LN}$ Max diameter $>22 \mathrm{~mm}(\mathrm{p}=0.0052)$, and LN Max diameter $(\mathrm{HR}=0.65, \mathrm{p}=0.012)$ was significant on multivariate analysis for OS. In the present study, LN Max diameter was also an independent prognostic factor in the multivariate analysis for OS. The 3-year OS was $39.7 \%$ with an MST of 25.5 months for LN Max diameter 


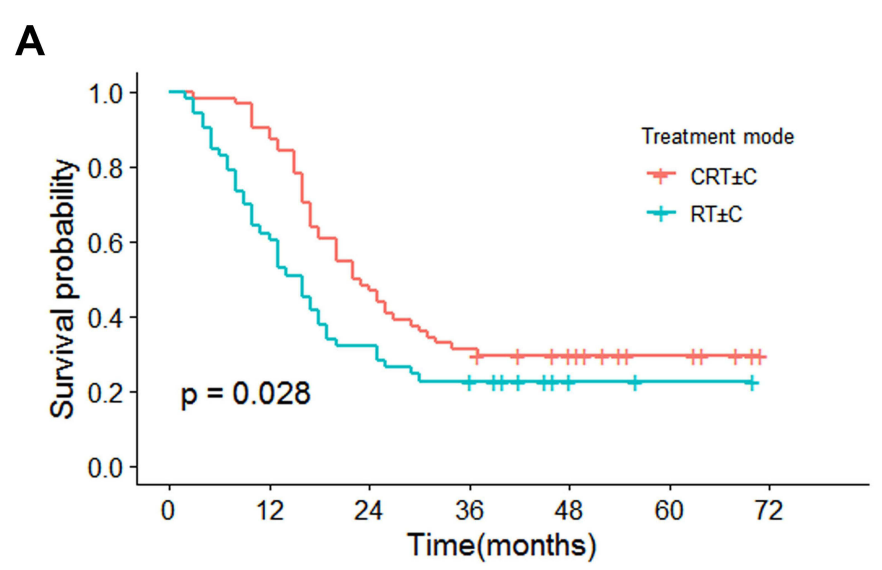

Number at risk

\begin{tabular}{|c|c|c|c|c|c|c|c|}
\hline $\begin{array}{r}\mathrm{CRT} \pm \mathrm{C} \\
\mathrm{RT} \pm \mathrm{C}\end{array}$ & $\begin{array}{l}64 \\
53\end{array}$ & $\begin{array}{l}58 \\
33\end{array}$ & $\begin{array}{l}31 \\
17\end{array}$ & $\begin{array}{l}20 \\
12\end{array}$ & $\begin{array}{c}15 \\
3\end{array}$ & $\begin{array}{l}6 \\
1\end{array}$ & $\begin{array}{l}0 \\
0\end{array}$ \\
\hline & 0 & 12 & 24 & $\begin{array}{r}36 \\
\text { ne }\end{array}$ & $\begin{array}{l}48 \\
\text { ths) }\end{array}$ & 60 & 72 \\
\hline
\end{tabular}

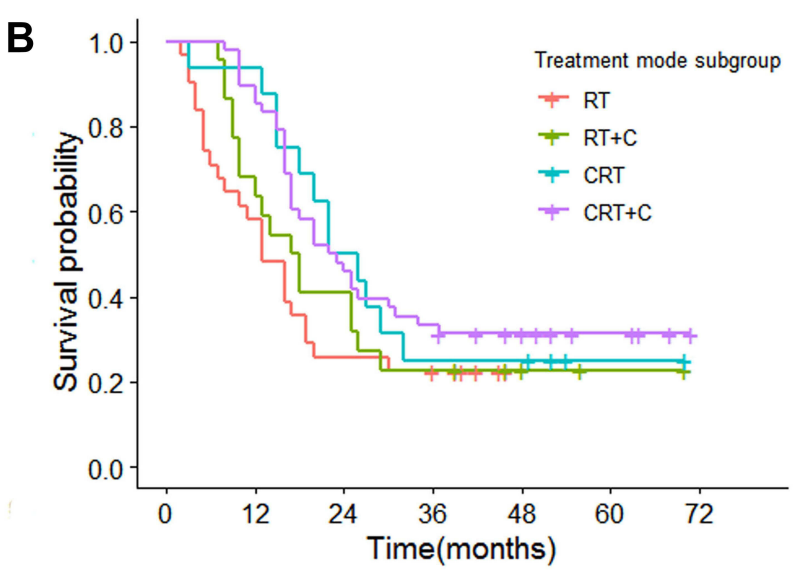

Number at risk

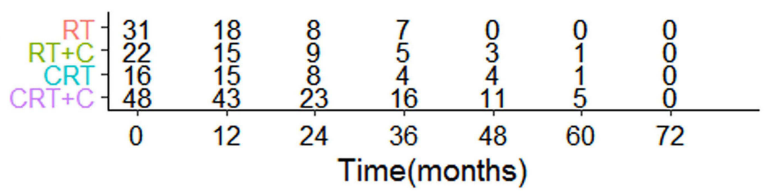

Figure 3 (A) Kaplan-Meier estimates of overall survival curves for different salvage treatment modes; (B) Kaplan-Meier estimates of overall survival curves for different subgroup salvage treatment modes.

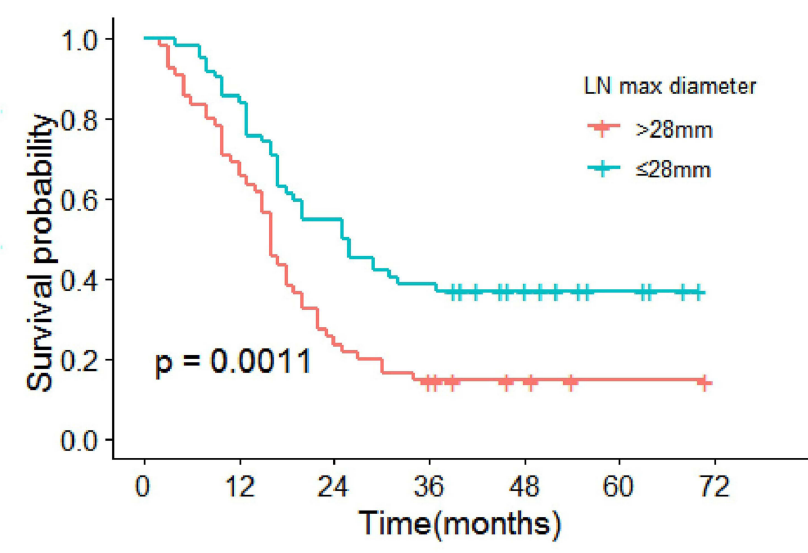

Number at risk

$\leq 28 \mathrm{~mm}=$\begin{tabular}{ccccccc}
55 & 38 & 14 & 8 & 3 & 1 & 0 \\
62 & 53 & 34 & 24 & 15 & 6 & 0 \\
\hline 0 & 12 & 24 & 36 & 48 & 60 & 72 \\
\multicolumn{7}{r}{ Time(months) }
\end{tabular}

Figure 4 Kaplan-Meier estimates of overall survival for LN Max diameter.

$\leq 28 \mathrm{~mm}$, and the 3-year OS was $14.5 \%$ with an MST of 16 months for LN Max diameter $>28 \mathrm{~mm}(\mathrm{p}=0.0011)$. Although local recurrence might have a relationship with the occurrence of distant metastasis, controlling local lesions also potentially affected survival as a whole. In this study, the response group had a better OS than the non-response group ( $\mathrm{p}=0.00024$, Figure 1) and found tumor response was one of the independent predictors of
OS in multivariate analysis ( $p<0.000$, Table 2$)$, consistent with the report of Bao. ${ }^{20}$

Although the RT or CRT is an effective salvage treatment for LN recurrence after curative resection of ESCC, the survival varied greatly, with the MST ranged between 13.3 and 43 months in the CRT group and between 10.8 and 22 months in the RT group. Several factors may

Table 2 Multivariate Analysis

\begin{tabular}{|c|c|c|c|}
\hline Factor & HR & $95 \% \mathrm{Cl}$ & P-value \\
\hline $\begin{array}{l}\text { Pathological TNM stage } \\
\qquad \begin{array}{l}\text { la }+ \text { lb } \\
\text { Ila }+ \text { Ilb } \\
\text { Illa }+ \text { IIlb }\end{array}\end{array}$ & $\begin{array}{l}1 \\
1.61 \\
1.96\end{array}$ & $\begin{array}{l}0.78-3.30 \\
0.98-3.92\end{array}$ & $\begin{array}{l}0.193 \\
0.057\end{array}$ \\
\hline $\begin{array}{l}\text { LN Max diameter } \\
\quad \leq 28 \mathrm{~mm} \\
\quad>28 \mathrm{~mm}\end{array}$ & $\begin{array}{l}\text { I } \\
2.07\end{array}$ & $1.33-3.32$ & 0.012 \\
\hline $\begin{array}{l}\text { No. of LN metastasis } \\
\text { Mono } \\
\text { Multiple }\end{array}$ & $\begin{array}{l}1 \\
1.51\end{array}$ & $0.95-2.40$ & 0.080 \\
\hline $\begin{array}{l}\text { Salvage Treatments } \\
\qquad \mathrm{RT} \pm \mathrm{C} \\
\text { CRT } \pm \mathrm{C}\end{array}$ & $\begin{array}{l}\text { I } \\
0.75\end{array}$ & $0.48-1.64$ & 0.198 \\
\hline $\begin{array}{l}\text { Tumor response } \\
\text { Response (CR+PR) } \\
\text { No-response (SD+PD) }\end{array}$ & $\begin{array}{l}\text { I } \\
2.43\end{array}$ & $1.53-3.90$ & $<0.000$ \\
\hline
\end{tabular}


account for this discrepancy. First, selection bias may occur in retrospective studies, small sample sizes and mono-institutional studies in most research. Second, chemotherapy regimens of CRT were diverse. Zhang et $\mathrm{al}^{24}$ reported that ESCC patients with postoperative $\mathrm{LN}$ recurrence who received the paclitaxel + CDDP (TP) regimen had significantly improved median OS than those receiving the FP regimen (16.3 months vs 9.8 months, $\mathrm{p}=$ 0.012). The sub-group analysis of the Kawamoto et $\mathrm{al}^{15}$ study showed that treatment outcomes with DOC alone combined with RT (MST, 14 months; 3-year OS rate, $30.5 \%$ ) were worse than those with FP combined RT (MST, 25 months; 3-year OS rate, 43.9\%), suggesting that CDDP may be a key drug in CRT treatment for postoperative LN recurrence of ESCC. But the sub-group analysis in the present study showed that MST and 3 -year OS of the 17 patients who received the $\mathrm{T}$ regimen were not worse than those of the 31 patients receiving the $\mathrm{TP}$ regimen $(\mathrm{p}=0.25)$. Third, the inclusion criteria are somewhat different. Some studies included patients with anastomotic recurrence and upper abdominal LN recurrence showing worse survival than those with the bilateral supraclavicular and mediastinum LN recurrence. ${ }^{8,25}$ Some studies did not exclude patients with postoperative adjuvant chemotherapy or RT. Zhou et $\mathrm{al}^{16}$ reported that 1 - and 3-year OS after salvage CRT in patients without postoperative adjuvant chemotherapy or RT were better than those receiving postoperative adjuvant chemotherapy or RT $(\mathrm{P}=0.0005)$. In this study, a total of $41 \%$ of patients received adjuvant chemotherapy, but we found that postoperative adjuvant chemotherapy was not associated with prognosis.

No previous studies have examined the effectiveness of consolidation chemotherapy (CCT) after CRT for treating postoperative LN recurrences of ESCC. However, there are no large-scale clinical trials, and there is no unanimous conclusion on the efficacy of CCT after CRT in nonsurgical EC patients. ${ }^{26-29}$ A systematic review, ${ }^{30}$ including 11 retrospective studies and 2008 patients, showed that CCT after CRT provided remarkable survival benefits in EC patients. In the present study, we analysed the efficacy of CCT after CRT or RT for treating postoperative LN recurrences of ESCC. Although CCT improved MST and 3-year OS of patients, there was no statistically significant difference compared to CRT or RT (Figure 3). The current retrospective study has limitations, and further clinical trials are required to evaluate the efficacy of CCT in ESCC patients with LN recurrences.

The present study has several limitations associated with its retrospective design. This study did not evaluate whether the irradiation field affected clinical outcomes. Involved-field CRT may reduce the incidence of treatment toxicity compared to elective nodal irradiation, and it was a treatment option worth considering for $\mathrm{LN}$ recurrence of ESCC. ${ }^{31}$ Moreover, there were some selection biases, and large-scale prospective studies are necessary to confirm these findings.

\section{Conclusion}

Salvage CRT or RT was a safe and effective treatment for LN recurrence after oesophagectomy in ESCC. Patients with the small LN Max diameter $(\leq 28 \mathrm{~mm})$ and obtained response after salvage therapy appeared to achieve longterm OS.

\section{Abbreviations}

EC, oesophageal cancer; ESCC, esophageal squamous cell cancer; LN, lymph node; CRT, chemoradiotherapy; RT, radiotherapy; $\mathrm{CT}$, computed tomography; 3DRT, threedimensional conformal radiation therapy; GTV, Gross tumor volume; CTV, Clinical target volume; PTV, Planning target volume; POST-C, postoperative adjuvant chemotherapy; T, paclitaxel; CDDP, cisplatin; OS, overall survival; MST, median survival time; CI, confidence interval; HR, hazard ratio.

\section{Data Sharing Statement}

The data used to support the findings of this study are available from the corresponding author upon request.

\section{Ethics Approval and Consent to Participate}

The study was approved by the ethics committee of Taixing people's Hospital (XJS20200022) and was performed in accordance with the standards of the Declaration of Helsinki. Written informed consent was obtained from all participants in the study.

\section{Funding}

There is no funding to report.

\section{Disclosure}

All authors reported no conflicts of interest for this work. 


\section{References}

1. Bray F, Ferlay J, Soerjomataram I, Siegel RL, Torre LA, Jemal A. Global cancer statistics 2018: GLOBOCAN estimates of incidence and mortality worldwide for 36 cancers in 185 countries. CA Cancer J Clin. 2018;68:394-424. doi:10.3322/caac.21492

2. Mariette C, Balon JM, Piessen G, Fabre S, Van Seuningen I, Triboulet JP. Pattern of recurrence following complete resection of esophageal carcinoma and factors predictive of recurrent disease. Cancer. 2003;97:1616-1623. doi:10.1002/cncr.11228

3. Natsugoe S, Matsumoto M, Okumura H, et al. Clinical course and outcome after esophagectomy with three-field lymphadenectomy in esophageal cancer. Langenbecks Arch Surg. 2010;395:341-346. doi:10.1007/s00423-010-0592-7

4. Hsu PK, Wang BY, Huang CS, Wu YC, Hsu WH. Prognostic factors for post-recurrence survival in esophageal squamous cell carcinoma patients with recurrence after resection. $J$ Gastrointest Surg. 2011;15:558-565. doi:10.1007/s11605-011-1458-1

5. Oppedijk V, van der Gaast A, van Lanschot JJ, et al. Patterns of recurrence after surgery alone versus preoperative chemoradiotherapy and surgery in the CROSS trials. J Clin Oncol. 2014;32:385-391. doi:10.1200/JCO.2013.51.2186

6. Liu J, Cai X, Liu Q, Li H, Cheng Y, Fu X. Characteristics of the local recurrence pattern after curative resection and values in target region delineation in postoperative radiotherapy for lower thoracic esophageal squamous cell cancer. Thorac Cancer. 2017;8:630-633.

7. Ni W, Yang J, Deng W, et al. Patterns of recurrence after surgery and efficacy of salvage therapy after recurrence in patients with thoracic esophageal squamous cell carcinoma. BMC Cancer. 2020;20:144. doi:10.1186/s12885-020-6622-0

8. Nakamura T, Ota M, Narumiya K, et al. Multimodal treatment for lymph node recurrence of esophageal carcinoma after curative resection. Ann Surg Oncol. 2008;15:2451-2457. doi:10.1245/ s10434-008-0016-x

9. Depypere L, Lerut T, Moons J, et al. Isolated local recurrence or solitary solid organ metastasis after esophagectomy for cancer is not the end of the road. Dis Esophagus. 2017;30:1-8.

10. Watanabe M, Mine S, Yamada K, et al. Outcomes of lymphadenectomy for lymph node recurrence after esophagectomy or definitive chemoradiotherapy for squamous cell carcinoma of the esophagus. Gen Thorac Cardiovasc Surg. 2014;62:685-692. doi:10.1007/ s11748-014-0444-4

11. Ma X, Zhao K, Guo W, et al. Salvage lymphadenectomy versus salvage radiotherapy/chemoradiotherapy for recurrence in cervical lymph node after curative resection of esophageal squamous cell carcinoma. Ann Surg Oncol. 2015;22:624-629. doi:10.1245/s10434-014-4008-8

12. Schizas D, Lazaridis II, Moris D, et al. The role of surgical treatment in isolated organ recurrence of esophageal cancer-a systematic review of the literature. World J Surg Oncol. 2018;16:55. doi:10.1186/ s12957-018-1357-y

13. Fakhrian K, Gamisch N, Schuster T, Thamm R, Molls M, Geinitz H. Salvage radiotherapy in patients with recurrent esophageal carcinoma. Strahlenther Onkol. 2012;188:136-142. doi:10.1007/s00066-011-0023-x

14. Yamashita H, Jingu K, Niibe Y, et al. Definitive salvage radiation therapy and chemoradiation therapy for lymph node oligo-recurrence of esophageal cancer: a Japanese multi-institutional study of 237 patients. Radiat Oncol. 2017;12:38. doi:10.1186/s13014-017-0780-5

15. Kawamoto T, Nihei K, Sasai K, Karasawa K. Clinical outcomes and prognostic factors of chemoradiotherapy for postoperative lymph node recurrence of esophageal cancer. Jpn J Clin Oncol. 2018;48:259-264. doi:10.1093/jjco/hyx171

16. Zhou YQ, Ding NX, Wang LJ, Liu W, Jiang M, Lu JC. Salvage radiochemotherapy for lymph node recurrence after radical surgery of esophageal cancer. Medicine (Baltimore). 2018;97:e9777. doi:10.1097/MD.0000000000009777
17. Chen J, Yin W, Yao H, Gu W. Salvage treatment for lymph node recurrence after radical resection of esophageal squamous cell carcinoma. Radiat Oncol. 2019;14:169. doi:10.1186/s13014-019$1377-\mathrm{y}$

18. Eisenhauer EA, Therasse P, Bogaerts J, et al. New response evaluation criteria in solid tumours: revised RECIST guideline (version 1.1). Eur J Cancer. 2009;45:228-247. doi:10.1016/j.ejca.2008.10.026

19. Ninomiya I, Okamoto K, Fushida S, et al. Survival benefit of multimodal local therapy for repeat recurrence of thoracic esophageal squamous cell carcinoma after esophagectomy. Esophagus. 2019;16:107-113. doi:10.1007/s10388-018-0638-4

20. Bao Y, Liu S, Zhou Q, et al. Three-dimensional conformal radiotherapy with concurrent chemotherapy for postoperative recurrence of esophageal squamous cell carcinoma: clinical efficacy and failure pattern. Radiat Oncol. 2013;8:241. doi:10.1186/1748-717X-8-241

21. Kobayashi R, Yamashita H, Okuma K, Shiraishi K, Ohtomo K, Nakagawa K. Salvage radiation therapy and chemoradiation therapy for postoperative locoregional recurrence of esophageal cancer. Dis Esophagus. 2014;27:72-78. doi:10.1111/dote.12068

22. Ma DY, Tan BX, Liu M, Li XF, Zhou YQ, Lu Y. Concurrent three-dimensional conformal radiotherapy and chemotherapy for postoperative recurrence of mediastinal lymph node metastases in patients with esophageal squamous cell carcinoma: a Phase 2 single-institution study. Radiat Oncol. 2014;9:28. doi:10.1186/1748-717X-9-28

23. Shi Y, Ge X, Gao Z, Liu S, Sun X, Luo J. Gross tumor volume is an independent prognostic factor in patients with postoperative locoregional recurrence of esophageal squamous cell carcinoma. Oncol Lett. 2019;18:2388-2393.

24. Zhang J, Peng F, Li N, et al. Salvage concurrent radio-chemotherapy for post-operative local recurrence of squamous-cell esophageal cancer. Radiat Oncol. 2012;7:93. doi:10.1186/1748-717X-7-93

25. Jingu K, Matsushita H, Takeda K, et al. Long-term results of radiotherapy combined with nedaplatin and 5-fluorouracil for postoperative loco-regional recurrent esophageal cancer: update on a Phase II study. BMC Cancer. 2012;12:542. doi:10.1186/1471-2407-12-542

26. Kim DE, Kim UJ, Choi WY, et al. Clinical prognostic factors for locally advanced esophageal squamous carcinoma treated after definitive chemoradiotherapy. Cancer Res Treat. 2013;45:276-284. doi:10.4143/crt.2013.45.4.276

27. Wu SX, Li XY, Xu HY, et al. Effect of consolidation chemotherapy following definitive chemoradiotherapy in patients with esophageal squamous cell cancer. Sci Rep. 2017;7:16870. doi:10.1038/s41598017-17254-9

28. Chen H, Zhou L, Yang Y, Yang L, Chen L. Clinical effect of radiotherapy combined with chemotherapy for non-surgical treatment of the esophageal squamous cell carcinoma. Med Sci Monit. 2018;24:4183-4191. doi:10.12659/MSM.910326

29. Chen M, Shen M, Lin Y, et al. Adjuvant chemotherapy does not benefit patients with esophageal squamous cell carcinoma treated with definitive chemoradiotherapy. Radiat Oncol. 2018;13:150. doi:10.1186/s13014-018-1086-y

30. Xia X, Liu Z, Qin Q, et al. Long-term survival in nonsurgical esophageal cancer patients who received consolidation chemotherapy compared with patients who received concurrent chemoradiotherapy alone: a systematic review and meta-analysis. Front Oncol. 2020;10:604657. doi:10.3389/fonc.2020.604657

31. Kawamoto T, Nihei K, Sasai K, Karasawa K. Involved-field chemoradiotherapy for postoperative solitary lymph node recurrence of esophageal cancer. Esophagus. 2018;15:256-262. doi:10.1007/ s10388-018-0622-z 


\section{Publish your work in this journal}

Cancer Management and Research is an international, peer-reviewed open access journal focusing on cancer research and the optimal use of preventative and integrated treatment interventions to achieve improved outcomes, enhanced survival and quality of life for the cancer patient.
The manuscript management system is completely online and includes a very quick and fair peer-review system, which is all easy to use. Visit http://www.dovepress.com/testimonials.php to read real quotes from published authors. 